\title{
The Impact of Ethnicity on the Incidence, Tumor Characteristics and Treatment of Ductal Carcinoma in Situ-An 11-Year Clinical Experience at a High Volume Teaching Hospital
}

\author{
Lauren S. Sparber ${ }^{1}$, Vijayashree Murthy ${ }^{1}$, Ronald S. Chamberlain 1,2,3* \\ ${ }^{1}$ Department of Surgery, Saint Barnabas Medical Center, Livingston, NJ, USA \\ ${ }^{2}$ Department of Surgery, New Jersey Medical School, Rutgers University, Newark, NJ, USA \\ ${ }^{3}$ Saint George's University School of Medicine, Grenada, West Indies \\ Email: *rchamberlain@barnabashealth.org
}

Received 13 July 2016; accepted 9 August 2016; published 12 August 2016

Copyright (C) 2016 by authors and Scientific Research Publishing Inc.

This work is licensed under the Creative Commons Attribution International License (CC BY). http://creativecommons.org/licenses/by/4.0/

c) (i) Open Access

\section{Abstract}

Introduction: Screening mammography has led to a marked increase in detection of in situ breast tumors in the United States. The University of Southern California/Van Nuys Prognostic Index (USC/VNPI) predicts the recurrence rates of ductal carcinoma in situ (DCIS); however variations in tumor characteristics, USC/VNPI scores, receptor and human epithelial growth factor receptor (HER)-2/neu status across different ethnicities/races have not been well studied. This study aimed to evaluate the racial trends in incidence, patient demographics, tumor characteristics and treatment variations for patients with DCIS at a high volume teaching hospital. Methods: 395 women underwent surgical intervention for DCIS between 2000 and 2011. Their race/ethnicity was divided into five mutually exclusive categories and demographic and clinicopathological data was collected. Multivariate analysis was performed to evaluate variations in patient and tumor factors with respect to age, size and surgical management among different ethnicities and races. Results: 82.1\% of Caucasian women underwent simple mastectomy with sentinel lymph node biopsy (SLNB) while lumpectomy with SLNB was highest in Hispanics $(40 \%, p=0.005)$. Overall, there was no significant difference in the incidence of receptor or $H E R-2 / n e u$ positivity, multicentricity, necrosis or grade of DCIS in the various racial groups, but there was a significant racial difference in the USC/ VNPI scores $(p<0.001)$. Conclusion: On a community level, screening detected DCIS accounted for the vast majority of DCIS diagnosed, which reflected national trends. Although no racial variation

\footnotetext{
${ }^{*}$ Corresponding author.
} 
in DCIS with respect to patient or tumor characteristics was observed, a racial difference in USC/ VNPI score was identified among the Hispanic population. Additional studies are required to validate the significance of these findings.

\section{Keywords}

Ductal Carcinoma in Situ, HER-2/Neu, Ethnicity, Race, Breast Neoplasms

\section{Introduction}

Ductal carcinoma in situ (DCIS) is defined as the proliferation of malignant mammary epithelial cells that have not yet invaded the basement membrane [1]. DCIS accounts for more than $20 \%$ of newly diagnosed breast cancers in the United States, in part due to increased mammography screening which began in the 1980's [1]-[4]. In the United States, 57,650 cases of DCIS were diagnosed in 2011 [5]. Mammography is currently the gold standard to diagnose DCIS; however, $6 \%$ - 23\% of DCIS lesions are not visible on mammography but may be detected by Magnetic Resonance Imaging (MRI) [6]. Prior to mammography, DCIS accounted for less than $1 \%$ of all breast cancers and was primarily an incidental pathologic finding at surgical resection [1] [7] [8].

Ethnic/racial variations among women with invasive breast cancer have been well studied [5] [9]. According to the American Cancer Society, a rapid increase in breast cancer incidence (4.1\% per year) among white women occurred in the 1980's [10]. Liu et al. [9] examined the incidence trends of invasive breast cancer by race/ ethnicity and age, noting that age-adjusted incidence rates (AAIRs) of invasive breast cancer rose equally among all races/ethnicities in Los Angeles County during 1980 through 2000. However, from 2004 to 2008, using data from the North American Association of Central Cancer Registries (NAACCR), Desantis et al. [5] analyzed incidence rates by race/ethnicity, finding that invasive breast cancer rates were stable among all racial/ethnic groups, but not equal. The highest incidence rate for breast cancer was reported among white women (125.4 cases per 100,000 females), followed by African American women (116.1 cases per 100,000 females) while the lowest incidence rate was observed in Asian American/Pacific Islander women (84.9 cases per 100,000 females) [5]. The 5-year disease-free survival rate among Asian American/Pacific Islander women is reported as 90.3\% and $77.5 \%$ in African-American women [5]. While these differences in survival rates for invasive breast cancer suggest differences in tumor biology, stage of diagnosis, and access to treatment among different ethnicities, the same information for DCIS is lacking.

The overall prognosis for DCIS is excellent with a 10-year survival rate of over 98\% [11] [12]. However, whether that translates across all races is an important question that needs to be answered. Studies at the national level have compared the incidence of DCIS in Caucasian to African American women and revealed a higher incidence among Caucasians; however this has not been well studied in other races/ethnicities [13]-[16]. Based on the National Cancer Institute's Surveillance, Epidemiology, and End Results (SEER) database trends in incidence of DCIS from 1972-1992, Ernster et al. [14] noted that the incidence of DCIS among all races rose 557\% and after 1983, DCIS rates for African-American women increased at a rate of 3.8 to 14.4 per 100,000 while in Caucasian women it increased from 3.7 to 15.9 per 100,000. The alarming rise of DCIS in the United States warrants additional research with regards to patient and tumor characteristics in patients of different ethnic/racial groups to determine whether such factors as family history of invasive/in situ breast cancer, breast cancer (BRCA) gene mutations, tumor grade, tumor size, receptor and human epithelial growth factor receptor (HER)2/neu patterns play a role. The University of Southern California/Van Nuys Prognostic Index (USC/VNPI) is a prognostic tool first described in 1996 that utilizes five factors (tumor size, margin width, nuclear grade, presence or absence of necrosis and age) to assess the risk of DCIS recurrence [17]. Racial variations in USC/VNPI scores may be important to predict recurrence patterns. This study sought to examine ethnic/racial trends in the incidence, tumor characteristics, patterns of care and USC/VNPI scores in DCIS patients admitted at a high volume tertiary care university affiliated medical center over an 11-year period.

\section{Methods}

Three hundred ninety-five women underwent surgical resection for DCIS at the Saint Barnabas Medical Center, 
Livingston, NJ, between February 2000 and July 2011 and were included in the study after approval from the Institutional Review Board (IRB \#11-48). Demographic and clinicopathological data including age, sex, ethnic/racial origin, family history of breast cancer, BRCA 1or 2 gene mutation, pre-operative radiological findings (including mammography, ultrasound and MRI), pre-operative clinical findings (including palpable versus nonpalpable), type of surgery [lumpectomy versus simple mastectomy; sentinel lymph node biopsy (SLNB)], histopathological and receptor characteristics of the tumor were collected on all patients. One-hundred and four patients had insufficient information on mode of detection. Patients with a previous diagnosis of invasive breast cancer or other pathology such as Lobular carcinoma in situ (LCIS) not associated with DCIS were excluded from the study.

The Estrogen Receptor (ER) and Progesterone Receptor (PR) assays were performed on formalin-fixed paraffin embedded tissue sections using monoclonal antibodies and the Bond Polymer Detection System. A total of 200 tumor cell nuclei were scored. The tests were performed with positive and negative controls that showed the expected appropriate responses. The HER-2/neu gene status was evaluated by interphase fluorescence in-situ hybridization (FISH) on formalin fixed paraffin embedded tissue section using a chromosome 17 centromeric probe (CEP17) and a HER-2 probe (LSI HER-2) from the FDA-approved Vysis PathVysion HER-2 DNA Probe Kit. The procedure was performed and with amplified and non-amplified controls that showed the expected appropriate results. The ratio is calculated as the average of HER-2/neu gene copy number to that of chromosome enumerator probe 17. A ratio greater than 2.2 denotes amplification of the HER-2/neu gene. If the ratio is less than 1.8, the HER-2/neu gene is not amplified while a ratio of 1.8 to 2.2 is considered equivocal for HER-2 gene amplification.

BRCA 1 and 2 mutations are sent to Myriad Genetics (Salt Lake City, Utah, USA) for BRACAnalysis®. Indications for performing BRCA testing include breast cancer diagnosed at age 50 or younger, ovarian cancer at any age, two primary breast cancers in the same individual or on the same side of the family, male breast cancer, triple negative breast cancer, pancreatic cancer with a breast or ovarian cancer in the same individual or on the same side of the family, Ashkenazi Jewish ancestry with an Hereditary Breast and Ovarian Cancer syndromeassociated cancer in the same individual or on the same side of the family, two or more relatives with breast cancer with one relative under age 50, three or more relatives with breast cancer at any age and/or a previously identified BRCA mutation in the family.

Race/ethnicity was grouped into five mutually exclusive categories. The categories were non-Hispanic Caucasian (hereafter referred to as Caucasian); non-Hispanic African-American (African-American); Hispanic; Asian-Pacific Islander (Asian) and Other/Unknown. The Asian-Pacific Islander category included Chinese, Japanese, Filipino and Asian Indian women. Patients whose race/ethnicity was not documented were analyzed in the other/unknown category.

Univariate analysis was performed using the Statistical Predictive Software and Solutions (SPSS) ${ }^{\mathrm{TM}}$ (v19, IBM, NY, USA) to evaluate ethnic variations in patient factors including age, family history and BRCA mutations as well as mode of detection (palpability versus screen detection). Surgical therapy provided included simple mastectomy with SLNB, simple mastectomy with ALND and lumpectomy with SLNB were similarly evaluated. Tumor factors analyzed were size, pathological type of DCIS, presence or absence of necrosis, grade, presence of invasive component or other pathology (LCIS), multifocality, multicentricity, Van Nuys Prognostic Index score, Estrogen Receptor (ER), Progesterone Receptor (PR) and HER-2/neu status.

\section{Results}

\subsection{Demographics (Table 1)}

Between February 2000 and July 2011, 395 female patients with a median age of 56 years (range: 28 - 91 years) underwent surgical therapy for Stage 0 (DCIS) breast cancer (Table 1). Race/ethnicity was unknown/not documented for 3.7\% $(n=15)$ of all DCIS cases. Among the 395 patients, $307(77.7 \%)$ women were Caucasian with a median age of 56 years (range: 28 - 91 years). African American women comprised 9.87\% $(n=39)$ of the total women in the study with a median age of 58 years (range of $36-79$ years). Hispanic women numbered 10 patients (2.53\%) with a median age of 51 years (range: 31 - 80 years). The Asian group was comprised of 24 women (6.07\%) with a median age of 55 years (range: 42 - 75 years). Fifteen (3.79\%) women were included in the Unknown/Other category and had a median age of 54 years (range: 37 - 76 years). There was no significant difference amongst the ethnic/racial groups with respect to age $(p=0.694)$. Overall, $56(14.2 \%)$ women had a 
Table 1. Patient characteristics, mode of detection and surgical treatment in 395 DCIS patients.

\begin{tabular}{|c|c|c|c|c|c|c|c|}
\hline Patient Characteristics & $\begin{array}{l}\text { Overall } \\
(\mathrm{n}=395)\end{array}$ & $\begin{array}{l}\text { Caucasian } \\
(\mathrm{n}=307)\end{array}$ & $\begin{array}{l}\text { African } \\
\text { American } \\
(\mathrm{n}=39)\end{array}$ & $\begin{array}{l}\text { Hispanic } \\
(\mathrm{n}=10)\end{array}$ & $\begin{array}{l}\text { Asian-Pacific } \\
\text { Islander } \\
(\mathrm{n}=24)\end{array}$ & $\begin{array}{l}\text { Unknown/ } \\
\text { Others } \\
(\mathrm{n}=15)\end{array}$ & $\begin{array}{c}p \\
\text { value }\end{array}$ \\
\hline Median age $(\mathrm{yr})^{\dagger}$ & 56 & 56 & 58 & 51 & 55 & 54 & 0.694 \\
\hline Family history & & & & & & & 0.362 \\
\hline $\begin{array}{l}1^{\text {st }} \text { degree relative } \\
\text { with breast cancer }\end{array}$ & $56(14.2 \%)$ & 49 (15.9\%) & $0(0.0 \%)$ & $2(20.0 \%)$ & $3(12.5 \%)$ & $2(13.3 \%)$ & \\
\hline BRCA 1 positive & $6(1.5 \%)$ & $5(1.6 \%)$ & $0(0.0 \%)$ & $0(0.0 \%)$ & $1(4.2 \%)$ & $0(0.0 \%)$ & \\
\hline BRCA 2 positive & $6(1.5 \%)$ & $4(1.3 \%)$ & $1(2.6 \%)$ & $0(0.0 \%)$ & $0(0.0 \%)$ & $1(6.7 \%)$ & \\
\hline Mode of detection: & & & & & & & 0.402 \\
\hline $\begin{array}{l}\text { Microcalcification } \\
\text { on MMG }\end{array}$ & 255 (64.6\%) & $191(62.2 \%)$ & 30 (76.9\%) & $7(70.0 \%)$ & $18(75.0 \%)$ & $9(60.0 \%)$ & \\
\hline Palpable mass & $36(9.1 \%)$ & 27 (8.8\%) & $5(12.8 \%)$ & $1(10.0 \%)$ & $1(4.2 \%)$ & $2(13.3 \%)$ & \\
\hline $\begin{array}{l}\text { Information not } \\
\text { available }\end{array}$ & $104(26.3 \%)$ & 89 (29.0\%) & $4(10.3 \%)$ & $2(20.0 \%)$ & $5(20.8 \%)$ & $4(26.7 \%)$ & \\
\hline Surgical treatment & & & & & & & 0.005 \\
\hline $\begin{array}{l}\text { Lumpectomy with } \\
\text { SLNB }\end{array}$ & $84(21.2 \%)$ & 55 (17.9\%) & $11(28.2 \%)$ & $4(40.0 \%)$ & $6(25.0 \%)$ & $8(53.3 \%)$ & \\
\hline $\begin{array}{l}\text { Simple mastectomy } \\
\text { with SLNB }\end{array}$ & 311 (78.7\%) & $252(82.1 \%)$ & 28 (71.8\%) & $6(60.0 \%)$ & $18(75.0 \%)$ & $7(46.6 \%)$ & \\
\hline
\end{tabular}

BRCA 1 = breast cancer susceptibility gene 1; BRCA 2 = breast cancer susceptibility gene 2; DCIS = ductal carcinoma in situ; MMG = mammogram; DCIS = ductal carcinoma in situ, SLNB = sentinel lymph node biopsy. ${ }^{*} p$ value statistically significant $<0.05$, for the trend; ${ }^{\dagger}$ median (range).

strong family history of breast cancer and 12 (3\%) were either BRCA 1 or BRCA 2 gene positive. Among this group, a family history of a first degree relative with breast cancer was highest among Hispanic $(20 \%, n=2)$ women. No significant ethnic or racial difference was noted with respect to family history of a first degree relative with breast cancer or gene mutation status $(p=0.362)$.

\subsection{Mode of Detection (Table 1)}

Screening mammography was the most common mode of DCIS detection across all groups (Table 1). Overall, 64.6\% $(n=255)$ of patients with DCIS were screen detected. Information on mode of detection was not available for $26.3 \%(\mathrm{~N}=104)$ of women. Screen detection was highest among African American women $(76.9 \%, \mathrm{n}=$ 30 ) and lowest among Caucasian $(62.2 \%, \mathrm{n}=191)$ women. Among the different groups, African American women $(12.8 \%, n=5)$ were most often found with a palpable mass compared with $4.2 \%(n=1)$ of Asian women. Although there were percentage differences amongst the different racial groups, mode of detection of DCIS among various races/ethnicities was not statistically significant $(p=0.402)$.

\subsection{Surgical Procedure (Table 1)}

All 395 patients were treated surgically by either lumpectomy with SLNB or simple mastectomy with SLNB as demonstrated in Table 1. Overall, 78.7\% $(n=311)$ of the women underwent simple mastectomy with SLNB while 21.2\% ( $\mathrm{n}=84)$ women underwent lumpectomy with SLNB. Lumpectomy with SLNB was most frequently observed in the Hispanic population $(40.0 \%, n=4)$ compared to $17.9 \%(n=55)$ of Caucasian women. $82.1 \%$ $(n=252)$ of Caucasian women underwent simple mastectomy followed by $75 \%(n=18)$ of Asian women. The type of surgery among races/ethnicities was statistically significant $(p=0.005)$. The results were further evaluated by subgroup analysis which demonstrated the significance within the Other group. More lumpectomies with SLNB were performed in the Other group compared with the Caucasian group. No significance within each group was found for surgical treatment.

\subsection{Histopathological Characteristics of the Tumor (Table 2)}

Table 2 illustrates the final histopathology for each DCIS patient treated. Median tumor size across all races/ethnicities was $1.0 \mathrm{~cm}$. Among the different groups, median tumor size varied such that in the Caucasian group it was $1.0 \mathrm{~cm}$ while in the African American group it was $0.2 \mathrm{~cm}$, but not statistically significant $(p=$ 
Table 2. Final histopathology and USC/Van Nuys prognostic index of 395 DCIS patients.

\begin{tabular}{|c|c|c|c|c|c|c|c|}
\hline Tumor Factors & $\begin{array}{c}\text { Overall } \\
(\mathrm{n}=395)\end{array}$ & $\begin{array}{c}\text { Caucasian } \\
(\mathrm{n}=307)\end{array}$ & $\begin{array}{l}\text { African } \\
\text { American } \\
(\mathrm{n}=39)\end{array}$ & $\begin{array}{l}\text { Hispanic } \\
(\mathrm{n}=10)\end{array}$ & $\begin{array}{l}\text { Asian-Pacific } \\
\text { Islander } \\
(\mathrm{n}=24)\end{array}$ & $\begin{array}{l}\text { Unknown/ } \\
\text { Others } \\
(\mathrm{n}=15)\end{array}$ & $p$ value ${ }^{*}$ \\
\hline Histopathology & & & & & & & 0.419 \\
\hline DCIS & 307 (77.7\%) & $242(78.8 \%)$ & $29(74.4 \%)$ & $7(70.0 \%)$ & $19(79.2 \%)$ & $10(66.7 \%)$ & \\
\hline DCIS with IDC & $70(17.7 \%)$ & $52(16.9 \%)$ & $6(15.4 \%)$ & $2(20.0 \%)$ & $5(20.8 \%)$ & $5(33.3 \%)$ & \\
\hline DCIS with LCIS & $18(4.6 \%)$ & $13(4.2 \%)$ & $4(10.3 \%)$ & $1(10.0 \%)$ & $0(0.0 \%)$ & $0(0.0 \%)$ & \\
\hline \multicolumn{8}{|l|}{ Tumor characteristics } \\
\hline $\begin{array}{l}\text { Median tumor } \\
\text { size }(\mathrm{cm})\end{array}$ & 1.0 & 1.0 & 0.2 & 0.1 & 0.1 & 0.1 & 0.861 \\
\hline Multicentricity & 47 (11.9\%) & $34(11.1 \%)$ & $5(12.8 \%)$ & $2(20.0 \%)$ & $3(12.5 \%)$ & $3(20.0 \%)$ & 0.772 \\
\hline Multifocality & $92(23.3 \%)$ & 72 (23.5\%) & $9(23.1 \%)$ & $3(30.0 \%)$ & 3 (12.5\%) & $5(33.3 \%)$ & 0.615 \\
\hline High Grade & $140(35.4 \%)$ & 107 (34.9\%) & $16(41.0 \%)$ & $3(30.0 \%)$ & $10(41.7 \%)$ & $4(26.7 \%)$ & 0.931 \\
\hline Comedonecrosis & 264 (66.8\%) & 199 (64.8\%) & $29(74.4 \%)$ & $7(70.0 \%)$ & $19(79.2 \%)$ & $10(66.7 \%)$ & 0.364 \\
\hline \multicolumn{8}{|l|}{ Receptor status } \\
\hline ER positive & 235 (59.5\%) & $182(81.3 \%)$ & $21(77.8 \%)$ & $9(90.0 \%)$ & $12(70.6 \%)$ & $11(84.6 \%)$ & 0.737 \\
\hline PR positive & $182(46.1 \%)$ & 139 (62.1\%) & $17(63.0 \%)$ & $7(70.0 \%)$ & $9(52.9 \%)$ & $10(79.6 \%)$ & 0.721 \\
\hline HER-2/neu positive & $24(6.1 \%)$ & $21(50.0 \%)$ & $2(50.0 \%)$ & $0(0.0 \%)$ & $0(0.0 \%)$ & $1(25.0 \%)$ & 0.469 \\
\hline $\begin{array}{l}\text { USC/Van Nuys } \\
\text { prognostic index }\end{array}$ & & & & & & & $<0.001$ \\
\hline Low score & $130(32.9 \%)$ & $103(33.6 \%)$ & $15(38.5 \%)$ & $0(0.0 \%)$ & $5(20.8 \%)$ & $7(46.7 \%)$ & \\
\hline Intermediate score & $264(66.8 \%)$ & 204 (66.4\%) & $24(61.5 \%)$ & $10(100 \%)$ & $19(79.2 \%)$ & $7(46.7 \%)$ & \\
\hline High score & $1(0.3 \%)$ & $0(0.0 \%)$ & $0(0.0 \%)$ & $0(0.0 \%)$ & $0(0.0 \%)$ & $1(6.7 \%)$ & \\
\hline
\end{tabular}

DCIS = ductal carcinoma in situ; IDC = intraductal carcinoma; LCIS = lobular carcinoma in situ; USC/VNPI = University of Southern California/Van Nuys prognostic index. ${ }^{*} p$ value statistically significant $<0.05$, for the trend.

0.861). Pure DCIS was reported in $77.7 \%(\mathrm{n}=307)$ of all tumors and most frequently identified in the Asian population $(79.2 \%, n=19)$. DCIS with microinvasion was observed in $17.7 \%(n=70)$ of all tumors and most often detected among Asian (20.8\%, $n=5)$ women and Hispanic $(20.0 \%, n=2)$ women. Eighteen patients (4.6\%) had a final pathology of mixed DCIS and LCIS. Overall, final histopathology of the primary tumor amongst the races was not statistically significant $(p=0.419)$.

Tumor characteristics analyzed included multifocality, multicentricity, high grade and comedonecrosis. Among the 395 patients, 35.4\% $(n=140)$ of tumors were considered high grade which was identified most often in tumors of Asian women $(41.7 \%, \mathrm{n}=10)$ and African American women $(41 \%, \mathrm{n}=16)$. High grade DCIS was not statistically significant amongst the different ethnic/racial groups $(p=0.931) .66 .8 \%(\mathrm{n}=264)$ of all tumors analyzed revealed comedonecrosis. Among the different ethnic/racial groups, comedonecrosis was observed most often in tumors of Asian $(79.2 \%, n=19)$ women when compared to Caucasian $(64.8 \%, n=199)$ women. Overall, comedonecrosis did not differ statistically between groups $(p=0.364)$. Multicentricity was detected in $11.9 \%(n=47)$ of all tumors, with the highest rate among Hispanic $(20 \%, n=2)$ women and lowest rate among Caucasian $(11.1 \%, \mathrm{n}=34)$ women. Multicentricity was not statistically significant among the various ethnic/racial groups $(p=0.772)$. Multifocality was revealed in $23.3 \%(n=92)$ of all tumors with a similar rate detected in both Caucasian $(23.5 \%, \mathrm{n}=72)$ women and African American $(23.1 \%, \mathrm{n}=9$ ) women. Overall, multifocality did not yield statistical significance $(p=0.615)$.

ER and PR receptors and HER-2/neu status among the 395 patients were evaluated as illustrated in Table 2. ER positive receptors were observed in 235 (59.5\%) tumors while PR positive receptors were observed in 182 (46.1\%) tumors. ER and PR positive receptors were identified most frequently in the Hispanic population (90.0\% and $70.0 \%$, respectively). HER-2/neu positive tumors were highest in Caucasian $(50 \%, \mathrm{n}=21)$ and African 
American $(50 \%, \mathrm{n}=2)$ women. There was no statistical significance seen among the various races/ethnicities in ER receptor status ( $p=0.737)$, PR receptor status $(p=0.721)$ or HER-2/neu status $(p=0.469)$.

\subsection{University of Southern California/Van Nuys Prognostic Index (Table 2)}

Table 2 depicts the USC/Van Nuys Prognostic Index (USC/VNPI) calculated for all 395 DCIS patients. The USC/VNPI is calculated using tumor grade, presence or absence of comedonecrosis, margin width, tumor size along with age. A significant difference in tumor characteristics between the different races/ethnicities was detected $(p<0.001)$. Overall, 66.8\% $(\mathrm{n}=264)$ women had an intermediate USC/VNPI score with $100 \%(\mathrm{n}=10)$ of Hispanic women included in this group. On further subgroup analysis with Caucasian women as the control group, Hispanic women had a higher percentage of intermediate VNPI scores $(p=0.026)$. Overall, 32.9\% $(\mathrm{n}=$ 130) women had a low USC/VNPI score which was most frequently observed in African American women $(38.5 \%, \mathrm{n}=15)$.

\section{Discussion}

DCIS of the breast constitutes a growing subset of breast cancer diagnoses among women in the United States and comprises $20 \%$ of new breast cancer cases [1]-[4]. With the rising incidence of DCIS diagnoses, it is important to understand variations in patterns of presentation and management of this disease in different racial/ethnic groups. With the increased use of screening mammography in the United States, an increased incidence of DCIS was observed in the 1980's across all ethnicities [18]-[21]. Innos and Horn-Ross analyzed data from the California Cancer Registry (1988-1999) looking at racial/ethnic differences and trends in the incidence of DCIS in 11,798 California women and found that the percentages of DCIS across races were similar between White (11.9\%), Black (11.9\%), Hispanic (10.8\%) and Asian-Pacific Islander (14.9\%) women [21]. Joslyn identified DCIS among 41,245 women of different races in nine different geographic areas across the United States using SEER (1973-2000) [3]. The study reported the incidence of DCIS in White women to be 9.2\%, African American women 10.2\%, American Indian/Alaska native women 7.3\% and Asian-Pacific Islander women 15.0\% [3]. These results are consistent with the current study. However, in a study of 950 women from the New Mexico SEER affiliated program (1973-1994), Adams-Cameron et al. found that the rate of DCIS was highest in Caucasian (77.6\%) women followed by Hispanic (19.6\%) women [19]. Conversely in the data collected from the Detroit SEER Program (1996-2000) that evaluated 358 African American and Caucasian women with DCIS, Nassar et al. observed that African American $(61 \% ; \mathrm{n}=217)$ women were diagnosed more often with DCIS than Caucasian $(39 \%, \mathrm{n}=141)$ women [20].

Although the present study did not observe major differences in age adjusted incidence of DCIS between the various ethnic/racial groups (median age at presentation: 56 years), Innos and Horn-Ross have reported that although a steady increase was noted in all racial/ethnic groups, the increase in the age-adjusted incidence rate of DCIS (both in terms of absolute increase and percent change) was steepest among Asian-Pacific Islander women (from 15.0 in 1988 to 46.2 in 1999) compared to Hispanic women (from 12.4 in 1988 to 30.4 in 1999), Black women (from 24.5 in 1988 to 46.1 in 1999), and White women (from 35.0 in 1988 to 59.3 in 1999) [21]. When examined by age group, the estimated annual percentage change (EAPC) was significantly higher in AsianPacific Islander women age 50 - 64 years $(\mathrm{EAPC}=12.0$; 95\% CI, 9.3 - 14.6) compared with White women of a similar age (EAPC $=5.6 ; 95 \%$ CI 4.6 - 6.6) [21]. The only significant differences between racial/ethnic groups observed were for White women age 40 - 49 years $($ EAPC $=3.1$; 95\% CI, $1.3-5.0)$ and those $>65$ years (EAPC $=$ 6.1; 95\% CI, 5.3 - 6.8) [21]. Adams-Cameron et al. [19] found that Hispanics, non-Hispanic whites, and American Indians had stable rates of DCIS between 1973 and 1984. Beginning in 1985, rates for all groups combined steadily increased (averaging a 21\% increase per year) and by 1994, the DCIS incidence rate was 13.8 per 100,000 in non-Hispanic whites and 9.7 per 100,000 for Hispanics [19].

Several authors have reported that the prevalence of BRCA 1 and BRCA 2 mutations are similar in DCIS and invasive breast cancer [22]-[24]. However, there is limited data regarding family history, gene mutations and DCIS with respect to race/ethnicity. Nassar et al. evaluated the incidence of DCIS with respect to family history of breast cancer and race (Caucasian and African American) and found no significant association between the two ( $p$ = statistically not significant) [20]. They observed that 29.2\% African American women (21/72) and 23.4\% Caucasian (11/47) had a strong family history of breast cancer, compared to our study in which Hispanic women 
had the highest rate of a first degree relative with breast cancer (20\%), but the result was not statistically significant [20].

Screening mammography has been principally the most important method of detection for DCIS. The Detroit Medical Center/SEER program identified 136 women in whom both clinical and mammographic information was available and found that $88 \%$ overall presented with mammographic calcifications and $12 \%$ overall with a breast mass/density [20]. 16\% of African American $(n=13)$ and $9 \%$ of Caucasian $(n=5)$ women presented symptomatically (either as a breast mass, nipple discharge or pain) [20]. These results are consistent with the current study where $12.8 \%$ of African American and $8.8 \%$ Caucasian women presented with symptoms.

The primary treatment of DCIS is surgical excision via a breast conservation approach (BCS) or by mastectomy. Utilization of BCS for treatment of DCIS has increased significantly over time in all SEER sites, ranging from 56.8\% in Utah to $75.6 \%$ in Connecticut [3]. Adams-Cameron et al. found an increase in the use of BCS for the treatment of DCIS between 1985-1994 at the rate of 6\% per year, resulting in a BCS rate of 52\% in 1994 and they observed that use of BCS for DCIS did not vary significantly by age and ethnicity where Hispanics had a rate similar to that of Caucasian women [19]. BCS acceptance rates vary significantly by geographic region in that women receiving Medicare who live in southern and west central states have lower rates of BCS than women living in New England and far western states. Lower rates of BCS are also reported in rural areas within states, with fewer physicians, and in areas without a cancer center or radiation treatment facility [25]. More recently a trend towards the treatment of DCIS by mastectomy began in 2001 [26], raising concerns about over treatment or lack of patient involvement in decision making. In a study of the ethnic variations in treatment decisions for DCIS among 2647 women (70.2\% white, 18\% African Americans and $11.8 \%$ others), Katz et al. reported that African American women reported seeing more surgeons (40\% of African American women reported seeing two or more surgeons versus $27.6 \%$ of white women; $p<0.001$ ) and were more likely to undergo a mastectomy than their white counterparts (only $31.4 \%$ of African American women were informed about BCS versus $50.7 \%$ of white women; $p=0.029$ ) [26]. These results are in contrast to the current study in which mastectomy rates were highest in Caucasian (82.1\%) women, followed by Asians (75.0\%), then African Americans (71.8\%) and Hispanics (40\%) who underwent the most lumpectomies. The mastectomy procedure was based on extent of microcalcification as well as patient choice. Tseng et al. reported that African American women were less likely to be offered referrals for reconstruction and African American women along with Asian women had low rates of reconstruction compared with Caucasian women [27].

The goal of treating DCIS is to reduce local recurrence and progression to invasive cancer. Thus the receptor status of the tumor is an important predictive factor. Use of tamoxifen therapy has been shown to decrease local and contralateral occurrence of invasive and non-invasive breast disease [28]. Invasive breast cancer subtypes have distinct sociodemographic, anthropometric and reproductive characteristics. Trivers et al. found that ER/PR negative tumors were associated with African American race, obesity, having a first child at a young age and a recent birth [29]. Using the information of 1893 DCIS patients of the North Carolina Cancer Registry (1998-1999), Jackson et al. found that of the 278 women with data on hormone receptor status, $77 \%$ were hormone positive and $23 \%$ were hormone negative, with no significant differences found among racial groups [28]. These results are similar to the current study in which $59.5 \%$ of women were found to be hormone positive, but no statistical significance was observed between the different ethnic/racial groups.

Since DCIS represents a broad spectrum of breast disease with various treatment options, the USC/VNPI was created to assist in treatment formulation since a standardized method is not appropriate [17]. The USC/VNPI includes nuclear grade of the tumor, comedonecrosis, margin width, size of tumor and age of patient in the calculation of local recurrence risk. The USC/VNPI quantifies prognostic factors in DCIS and identifies specific groups of patients that may be offered excision alone, excision plus radiation or mastectomy [17]. The current study looked at the USC/VNPI scores among the different ethnic/racial groups. High grade and comedonecrosis, which is an indicator of a more aggressive DCIS, was highest among Asian (41.7\% and 79.2\% respectively) and African American women (41.0\% and $74.4 \%)$ while it was found at a relatively low rate among Caucasian women (34.9\% and 64.8\%). Although these findings were not independently significant, the factors were calculated into the USC/VNPI and subgroup analysis was performed. It was observed that there was a significant racial difference in the USC/VNPI score among Hispanic women $(p<0.001)$, notably $100 \%$ of Hispanic women were categorized as intermediate USC/VNPI score. This raises a point of concern with regards to their adjuvant treatment. Based on previous reports by Silverstein et al., treatment recommendations for the intermediate group are the most complicated and vary from no further treatment needed to recommending mastectomy [17]. How- 
ever, owing to the small sample size in this study, these results need to be validated on a larger scale. To date, there have been no studies of DCIS patients using the USC/VNPI and local recurrence patterns among the different ethnicities/races in addition to this small sample report. The results of such studies will aid in counseling DCIS patients of different ethnicities/races and allow the development of evidence based treatment options using parameters obtained after initial excision.

The current study has several limitations, notably the overall small sample size as well as the disparity between the Caucasian group and the rest of the groups. The patient population is predominantly Caucasian, which explains the differences. Further validation of these single institutional results are needed from a population based database analysis.

\section{Conclusion}

As mammographic detection of DCIS continues to rise, racial/ethnic variations in patient and tumor characteristics need to be appropriately studied. Presentation, extent and patterns of treatment (including awareness of reconstruction) selected by women of different ethnicities/races are highly variable. This study demonstrated that racial/ethnic variations in tumor characteristics were identified among patients treated for DCIS based on the USC/VNPI, specifically in the Hispanic population. Thus, the USC/VNPI may be uniquely suited to detect ethnic variation among DCIS patients. Additional research is underway to examine the interplay among USC/ VNPI scores, hormone receptor status, HER-2/neu status and recurrence patterns between the different ethnicities/races in a large population based database.

\section{References}

[1] Lippman, M. (2002) Why Study Ductal Carcinoma In-Situ? In: Silverstein, M.J., Recht, A. and Lagios, M., Eds., Ductal Carcinoma In-Situ of the Breast, 2nd Edition, Lippincott William and Wilkins, Philadelphia, 12-16.

[2] Liao, N., Zhang, G., Liu, Y., Li, X., Yao, M., Xu, F., et al. (2011) HER2-Positive Status Is an Independent Predictor for Coexisting Invasion of Ductal Carcinoma in Situ of the Breast Presenting Extensive DCIS Component. Pathology Research and Practice, 207, 1-7. http://dx.doi.org/10.1016/j.prp.2010.08.005

[3] Joslyn, S.A. (2006) Ductal Carcinoma in Situ: Trends in Geographic, Temporal, and Demographic Patterns of Care and Survival. The Breast Journal, 12, 20-27. http://dx.doi.org/10.1111/j.1075-122X.2006.00182.X

[4] Blackman, D.K., Bennett, E.M. and Miller, D.S. (1999) Trends in Self-Reported Use of Mammograms (1989-1997) and Papanicolaou Tests (1991-1997)—Behavioral Risk Factor Surveillance System. MMWR Surveillance Summaries, 48, 1-22.

[5] Desantis, C., Siegel, R., Bandi, P. and Jemal, A. (2011) Breast Cancer Statistics, 2011. CA: A Cancer Journal for Clinicians, 61, 409-418. http://dx.doi.org/10.3322/caac.20134

[6] Kim, J.A., Son, E.J., Youlk, J.H., Kim, E.K., Kim, M.J., Kwak, J.Y., et al. (2011) MRI Findings of Pure Ductal Carcinoma in Situ: Kinetic Characteristics Compared According to Lesion Type and Histopathologic Factors. American Journal of Roentgenology, 196, 1450-1456. http://dx.doi.org/10.2214/AJR.10.5027

[7] Silverstein, M.J. and Lagios, M.D. (2010) Ductal Carcinoma in Situ. In: Kuerer, H.M., Kuerer's Breast Surgical Oncology, The McGraw Hill Companies, New York, 189-208.

[8] Virnig, B.A., Tuttle, T.M., Shamliyan, T. and Kane, R.L. (2010) Ductal Carcinoma in Situ of the Breast: A Systematic Review of Incidence, Treatment, and Outcomes. Journal of the National Cancer Institute, 102, 170-178. http://dx.doi.org/10.1093/jnci/djp482

[9] Liu, L., Zhang, J., Wu, A.H., Pike, M.C. and Deapen, D. (2011) Invasive Breast Cancer Incidence Trends by Detailed Race/Ethnicity and Age. International Journal of Cancer, 130, 395-404. http://dx.doi.org/10.1002/ijc.26004

[10] Breast Cancer. American Cancer Society. http://www.cancer.org/acs/groups/cid/documents/webcontent/003090-pdf.pdf

[11] Schmale, I., Liu, S., Rayhanabad, J., Russell, C.A. and Sener, S.F. (2012) Ductal Carcinoma in Situ (DCIS) of the Breast: Perspectives on Biology and Controversies in Current Management. Journal of Surgical Oncology, 105, 212-220. http://dx.doi.org/10.1002/jso.22020

[12] Ernster, V.L., Barclay, J., Kerlikowske, K., Wilkie, H. and Ballard-Barbash, R. (2000) Mortality among Women with Ductal Carcinoma in Situ of the Breast in the Population Based Surveillance, Epidemiology and End Results Program. Archives of Internal Medicine, 160, 953-958. http://dx.doi.org/10.1001/archinte.160.7.953

[13] Schwartz, G.F., Solin, L.J., Olivotto, I.A., Ernster, V.L., Pressman, P., et al. (2000) The Consensus Conference on the Treatment of In Situ Ductal Carcinoma of the Breast, 22-25 April 1999. Breast, 9, 144-186. 
http://dx.doi.org/10.1054/brst.1999.0156

[14] Ernster, V.L., Barclay, J., Kerlikowski, K., Grady, D. and Henderson, I.C. (1996) Incidence of and Treatment for Ductal Carcinoma in Situ of the Breast. JAMA, 275, 913-918. http://dx.doi.org/10.1001/jama.1996.03530360023033

[15] Swanson, G.M., Ragheb, N.E., Lin, C.S., Hankey, B.F., Miller, B., Horn-Ross, P., et al. (1993) Breast Cancer among Black and White Women in the 1980s. Cancer, 72, 788-798. http://dx.doi.org/10.1002/1097-0142(19930801)72:3<788::AID-CNCR2820720326>3.0.CO;2-C

[16] Simon, M., Schwartz, A., Martino, S. and Swanson, G. (1992) Trends in the Diagnosis of in Situ Breast Cancer in the Detroit Metropolitan Area, 1973-1987. Cancer, 69, 466-469. http://dx.doi.org/10.1002/1097-0142(19920115)69:2<466::AID-CNCR2820690232>3.0.CO;2-7

[17] Silverstein, M.J. (2003) The University of Southern California/Van Nuys Prognostic Index for Ductal Carcinoma in Situ of the Breast. The American Journal of Surgery, 186, 337-343. http://dx.doi.org/10.1016/S0002-9610(03)00265-4

[18] Silverstein, M.J., Lagios, M.D., Recht, A., Allred, D.C., Harms, S.E., Holland, R., et al. (2005) Image Detected Breast Cancer: State of the Art Diagnosis and Treatment. Journal of the American College of Surgeons, 201, 586-597. http://dx.doi.org/10.1016/j.jamcollsurg.2005.05.032

[19] Adams-Cameron, M., Gilliland, F.D., Hunt, W.C. and Key, C.R. (1999) Trends in Incidence and Treatment for Ductal Carcinoma in Situ in Hispanic, American Indian, and Non-Hispanic White Women in New Mexico, 1973-1994. Cancer, 85, 1084-1090. http://dx.doi.org/10.1002/(SICI)1097-0142(19990301)85:5<1084::AID-CNCR11>3.0.CO;2-5

[20] Nassar, H., Bashar, S., Visvanathan, K. and Visscher, D. (2009) Ductal Carcinoma in Situ in African American versus Caucasian American Women: Analysis of Clinicopathologic Features and Outcome. Cancer, 115, 3181-3188. http://dx.doi.org/10.1002/cncr.24376

[21] Innos, K. and Horn-Ross, P.L. (2003) Recent Trends and Racial/Ethnic Differences in the Incidence and Treatment of Ductal Carcinoma in Situ of the Breast in California Women. Cancer, 97, 1099-1106. http://dx.doi.org/10.1002/cncr.11104

[22] Claus, E.B., Petruzella, S., Matloff, E. and Carter, D. (2005) Prevalence of BRCA1 and BRCA2 Mutations in Women Diagnosed with Ductal Carcinoma in Situ. JAMA, 293, 964-969. http://dx.doi.org/10.1001/jama.293.8.964

[23] Peto, J., Collins, N., Barfoot, R., Seal, S., Warren, W., Rahman, N., et al. (1999) Prevalence of BRCA1 and BRCA2 Gene Mutations in Patients with Early-Onset Breast Cancer. Journal of the National Cancer Institute, 93, 1811-1817. http://dx.doi.org/10.1093/jnci/91.11.943

[24] Innos, K. and Horn-Ross, P.L. (2008) Risk of Second Primary Breast Cancers among Women with Ductal Carcinoma in Situ of the Breast. Breast Cancer Research and Treatment, 111, 531-540. http://dx.doi.org/10.1007/s10549-007-9807-1

[25] Nattinger, A.B., Gottlieb, M.S., Veum, J., Yahnke, D. and Goodwin, J.S. (1992) Geographic Variation in the Use of Breast-Conserving Treatment for Breast Cancer. The New England Journal of Medicine, 326, 1102-1107. http://dx.doi.org/10.1056/NEJM199204233261702

[26] Katz, S.J., Lantz, P.M., Janz, N.K., Fagerlin, A., Schwartz, K., Liu, L., et al. (2005) Patient Involvement in Surgery Treatment Decisions for Breast Cancer. Journal of Clinical Oncology, 23, 5526-5533. http://dx.doi.org/10.1200/JCO.2005.06.217

[27] Tseng, J.F., Kronowitz, S.J., Sunn, C.C., Perry, A.C., Hunt, K.K., Babiera, G.V., et al. (2004) The Effect of Ethnicity on Immediate Reconstruction Rates after Mastectomy for Breast Cancer. Cancer, 101, 1514-1523. http://dx.doi.org/10.1002/cncr.20529

[28] Jackson, L.C., Camacho, F., Levine, E.A., Anderson, R.T. and Stewart IV, J.H. (2008) Patterns of Care Analysis among Women with Ductal Carcinoma in Situ in North Carolina. The American Journal of Surgery, 195, 164-169. http://dx.doi.org/10.1016/j.amjsurg.2007.10.001

[29] Trivers, K.F., Lund, M.J., Porter, P.L., Liff, J.M., Flagg, E.W., Coates, R.J., et al. (2009) The Epidemiology of TripleNegative Breast Cancer, Including Race. Cancer Causes \& Control, 20, 1071-1082. http://dx.doi.org/10.1007/s10552-009-9331-1 


\section{Submit or recommend next manuscript to SCIRP and we will provide best service for you:}

Accepting pre-submission inquiries through Email, Facebook, LinkedIn, Twitter, etc.

A wide selection of journals (inclusive of 9 subjects, more than 200 journals)

Providing 24-hour high-quality service

User-friendly online submission system

Fair and swift peer-review system

Efficient typesetting and proofreading procedure

Display of the result of downloads and visits, as well as the number of cited articles

Maximum dissemination of your research work

Submit your manuscript at: http://papersubmission.scirp.org/ 